九州大学学術情報リポジトリ

Kyushu University Institutional Repository

\title{
Taxonomic Studies on the Genus Trissolcus Ashmead of Japan and Korea (Hymenoptera, Scelionidae)
}

Ryu, Joon

Entomological Laboratory, Faculty of Agriculture, Kyushu University

Hirashima, Yoshihiro

Entomological Laboratory, Faculty of Agriculture, Kyushu University

https://doi.org/10.5109/23793

出版情報：九州大学大学院農学研究院紀要. 29 (1)，pp. 35-58，1984-09. Kyushu University バージョン：

権利関係 : 


\title{
Taxonomic Studies on the Genus Trissolcus Ashmead of Japan and Korea (Hymenoptera, Scelionidae)*
}

\author{
Joon Ryu** and Yoshihiro Hirashima \\ Entomological Laboratory, Faculty of Agriculture, \\ Kyushu University, Fukuoka 812, Japan \\ (Received May 21, 1984)
}

\begin{abstract}
The genus Trissolcus Ashmead of Japan and Korea is revised. Ten species are involved, 8 from Japan and 4 from Korea. Two new species, Trissolcus itoi Ryu from Japan and Korea and Trissolcus yamagishii Ryu from Korea, are described. New records include Trissolcus flavipes, T. delucchii and gonopsidis from Japan and $T$. flavipes and T. nigripedius from Korea.
\end{abstract}

This is a first part of our revisional work on the subfamily Telenominae of the faimily Scelionidae of Japan and Korea. This paper reports 10 species in all, 8 from Japan and 4 from Korea. Two new species, Trissolcus itoi Ryu from Japan and Korea and Trissolcus yamagishi Ryu from Korea, are described. Three species, Trissolcus favipes, T. delucchii and T. gonopsidis, are recorded from Japan and 2 species, T. flavipes and T. nigripedius, are recorded from Korea for the first time.

Our species of Trissolcus are divided into two groups, each of which may be recognizable at the subgeneric rank.

\section{Genus Trissolcus Ashmead, 1893}

Trissolcus Ashmead, 1893, Bull, U. S. nat. Mus., 45: 138, 161.

Asolcus Nakagawa, 1900, Spec. Rep. Imp. Agr. Exp. Stat. Jap., 6: 17.

Immsia Cameron, 1913, Indian For. Rec., 1912, 4: 104.

Microphanurus Kieffer, 1926, Das Tierreich, 48: 16, 91.

Type-species : Trissolcus brochymenae Ashmead, 1893

The genus Trissolcus is virtually world-wide and a relatively large group. This genus was erected by Ashmead in 1893 for the reception of six species. This is closely allied to Telenomus but is readily distinguished by the bare eyes, much broader metasoma and often abbreviated notauli. The two genera may also be distinguished biologically, i. e., the former almost exclusively parasi-

* Contribution from the Entomological Laboratory, Faculty of Agriculture, Kyushu University, Fukuoka (Ser. 3, No. 151).

** Present address : Korea Atomic Energy Research Institute, P. 0. Box 7, Cheong Ryang, Seoul, Korea. 
tizes the eggs of Heteroptera, and the latter predominantly the eggs of Lepidoptera.

Head transverse, broader than thorax; frons convex; occiput deeply concave. Ocelli triangularly arranged, widely separated, posterior ocelli only slightly separated from margin of eye and connected with it by an oblique grooved line. Eyes large, sub-ovate. Antennae inserted close to mouth part, in female 11-segmented, in male 12-segmented. Maxillary palpi 3-segmented. Mandibles bifid. Thorax convex; mesoscutum with or without notauli posteriorly; scutellum semicircular; metanotum very short. Fore wings pubescent; marginal vein usually short, stigma1 vein rather long; postmarginal vein long. Metasoma broadly oval, depressed, subsessile ; second tergum longest, but always broader than long. Legs as in Telenomus.

This genus may be divided into two groups according to the presence or absence of the notauli on the mesoscutum.

Group A: Notauli present. This group includes 5 species, i. e., Trissolcus flavipes, T. mitsukurii, T. delucchii, T. tumidus, and T. japonicus.

Group B: Notauli absent. This group includes 5 species, i. e., Trissolcus gonopsidis, T. itoi, T. yamagishii, T. elasmuchae and T. nigripedius.

Key to Japanese and Korean spectes (females) of Trissolcus

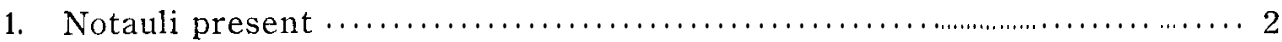

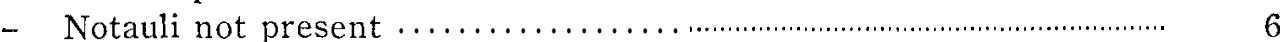

2. Vertex transversely sharply carinate behind, median portion of carina (behind mid ocellus) distinctly elevated; face largely covered with distinct concentric strigae above antennal toruli; lateral portions of face strongly convex; large species, length 1.7-2.0 mm ......................flavipes Thomson

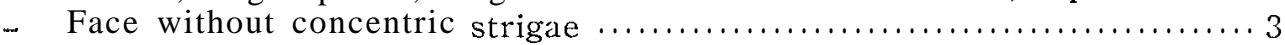

3. Scutellum coarsely sculptured (slightly more coarsely sculptured than in mesoscutum), dull ; club of antennae well formed (broad and long), black ; vertex between posterior ocelli not carinate; mid ocellus close to vertex, separated by not more than its diameter; frons and vertex strongly sculptured ; median portion of frons distinctly carinate ; length 1.3-1. $5 \mathrm{~mm}$

mitsukurii Ashmead

- Scutellum not coarsely sculptured, either smooth or weakly tessellate .... 4

4. Scutellum tessellate, dull; vertex transversely distinctly edged (carinate on lateral portion behind posterior ocelli) ; mid ocellus separated from vertex by more than its diameter; mesoscutum broadly rounded in front; antennae reddish brown except for club; femora not infuscated; length

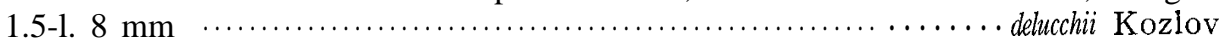

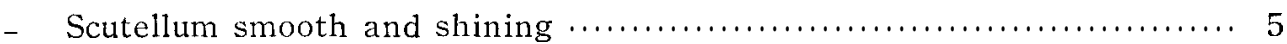

5. Preoccipital carina not present, althouth the portion distinctly edged; mid ocellus very close to vertex; pedicel subequal to first funicle segment; second funicle segment not longer than broad; length $1.3 \mathrm{~mm} . \ldots \ldots \ldots$.

tumidus Mayr

Preoccipital carina present but not very sharp; mid ocellus separated from vertex about by its diameter; space just in front of mid ocellus smooth and 
shining; pedicel shorter than first funicle segment; second funicle segment distinctly longer than broad ; length $1.4 \mathrm{~mm} \cdots \cdots$ japonicus (Ashmead)

6. Preoccipital carina present; scutellum densely reticulate, dull, much more finely sculptured than in mesoscutum; antennal club black, distinctly contrasting to the rest of antennae which is yellow; length $1.4 \mathrm{~mm} \ldots \ldots \ldots \ldots . . . .$. ...................................................... gonopsidis Watanabe

- Preoccipital carina absent, although the portion very well convex and

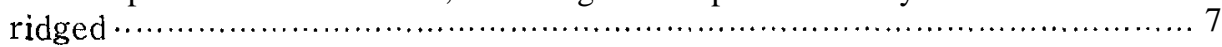

7. Scutellum strongly sculptured as in posterior part of mesoscutum $\cdots .8$

- Scutellum weakly tessellate, much less strongly sculptured than in posterior portion of mesoscutum.......................................... 9

8. Scutellum strongly sculptured with irregular wrinkles; antennae broadly black; length 1. 221. $25 \mathrm{~mm}$...................................itoi Ryu, sp. n. Very similar to the preceding species, but scutellum slightly less strongly sculptured; antennae yellowish brown on basal half; length $1.3 \mathrm{~mm}$

"yamagishii Ryu, sp. n.

9. Small species, length $1.0 \mathrm{~mm}$; head, as seen from above, frontal region well convex, therefore head is thick; longitudinal striae on second tergum weak even on medio-basal portion; antennae yellowish except for club and funicle which are dark brown ..................... elasmuchae Watanabe

- Larger, length about $1.2-1.5 \mathrm{~mm}$; head, as seen from above, transverse, moderately thick; longitudinal striae on second tergum distinct; antennae entirely blackish nigripedius Nakagawa

\section{Group A: Notauli present on mesoscutum}

(1) Trissolcus flavipes (Thomson, 1861)

(Figs. 3, 8, 23, 28)

Telenomus flavipes Thomson, 1861, Ofv. Svensk. Vet.-Akad. Forh., 18: 170, female.

Telenomus cultratus Mayr, 1879, Verh. zool.-bot. Ges. Wien., 29: 703, female and male.

A phanurus flavipes: Kieffer, in Andre, 1912, Spec.Hym. Eur., 11: 72, female and male.

Aphanurus cultratus: Kieffer, in Andre, 1912, Spec. Hym. Eur., 11: 17, female and male.

Microphanurus flavipes: Kieffer, 1926, Das Tierreich, 48: 91, 96, female.

Microphanurus cultratus: Kieffer, 1926, Das Tierreich, 48: 91, 95, female and male.

Microphanurus cultratus: Nixon, 1939, Arb. morph. taxon. Ent., Berlin-Dahlem, 6 (2): 133, female and male.

Asolcus cultratus: Masner, 1958, Trans. I. Int. Conf. Ins. Path. \& Biol. Cont., Praha: 378379.

Asolcus cultratus: Delucchi, 1961, Chiers Resch. Agr., 14: 51, female and male.

Trissolcus flavipes: Kozlov, 1968, Trudȳ vses. ent. Obshch., 52: 198, female and male.

Trissolcus flavipes: Kozlov and Le, 1976, Ent. Rev., Washington, 55 (3): 108.

This species is similar to mitsukurii, but differs from the latter in having the face above antennal toruli with concentric strigae, vertex transversely sharply carinate and median portion of carina distinctly elevated. This is further characterized by the lateral portions of face strongly convex and mososcutum strongly reticulate-sculptured and with notauli in the posterior portion. However, the coloration of antennae and legs are very variable. 
The antennal scape of some specimens are sometimes more darker than the following redescription.

Female: Black. Antennae yellowish brown except for club which is black. Legs yellowish brown, paler than antennal segments except for coxae which are black. Wings tinged with pale brown, veins yellowish brown.

Head transverse as seen from above, about 3.2 times as broad as its median length and hardly broader than thorax (9: 8.5). Vertex broad, rather flat, transversely sharply carinate, median portion of carina distinctly elevated and reticulate-sculptured throughout with sparse, short hairs; occiput broadly concave, closely reticulate throughout with sparse, short hairs. Frons well convex, coarsely reticulate-sculptured and with scattered punctures; face above antennal toruli distinctly concentric strigate up to mid ocellus. Subocular space strongly convex, reticulate rugose with scattered punctures. Eyes bare, 1.4 times as long as broad; interocular distance rather broad, about 1.2 times as long as eye as seen in front. Ocelli forming a large triangle; mid ocellus separated from vertex by more than its diameter; posterior ocellar distance about 1.9 times as long as lateral ocellar distance. Antennae rather stout; scape 5.3 times as long as broad, almost equal to next five segments combined; pedicel twice as long as broad, barely shorter than first funicle segment; second 1.4 times as long as broad, 0.7 times as long as first; third and fourth transverse ; club 5 -segmented, ratio of each segment as $1.9: 1.5: 1.5: 1.4$ : 1.9 in length, and $1.8: 1.9: 1.7: 1.6: 1.3$ in width.

Thorax well convex, a little broader than long (11: 10) ; mesoscutum distinctly convex, covered with rather short hairs, strongly reticulate sculptured and sharply defined notauli in the posterior portion; scutellum rather broad but transverse, reticulate-sculptured throughout and scrobiculate along the edge and covered with sparse hairs; metanotum very short, strongly sculptured. Fore wings broad, 2.5 times as long as broad; stigmalis rather long, 2.8 times as long as marginalis and 0.7 times as long as submarginalis. Hind wings 3.7 times as long as broad; fringes about $1 / 4$ of the greatest width of hind wing.

Metasoma rather broad, 1.2 times as long as broad; first tergum transverse, deeply longitudinally costate all over with sparse hairs in lateral portion ; second tergum about 1.5 times as broad as long, longitudinally striated on basal about $3 / 4$ with sparse hairs in lateral and posterior portion; third to seventh therga strongly transverse, punctulate and hairy throughout.

Length: $1.7-2.0 \mathrm{~mm}$.

Host: Carpocoris pundicus Poda (in USSR.), Palomena prasina L. (in Germany).

Distribution : Japan (Kyushu, Honshu, Hokkaido, Shikoku), Korea, USSR., Sweden, Germany, Austria. This is the first record of this species from Japan and Korea.

Specimens examined: JAPAN : 1 female, Ashoro, Tokachi, Hokkaido, 11-12. vi. 1958 (Y. Murakami) ; 1 female, Izuhara-A riakeyama, Tsushima, Nagasaki Pref., Kyushu, 25. ix. 1959 (Hidaka et al.); 1 female, Nose Myoken, Hyogo Pref., Honshu, 11. iv. 1976 (K. Ito); 4 females, Kanagurayama, Ojiya-shi, Niigata 
Pref., Honshu, 11. viii. 1970 (K. Yamagishi) ; 1 female, Kanagurayama, Ojiyashi, Niigata Pref., Honshu, 19. viii. 1970 (K. Yamagishi) ; 1 female, Rubesu, Shibetsu, Nemuro, Hokkaido, 25-28. viii. 1971 (K. Yamagishi). KOREA: 17 females, Mt. Sudo (1,000 m), Kyungsangpuk-do, Korea, 13-14. vii. 1971 (K. Yamagishi) ; 2 females, Mt. Sudo $(700$ m), Kyungsangpuk-do, Korea, 9-12. vii. 1971 (K.Yamagishi) ; 1 female, Mt. Sudo $(700 \mathrm{~m})$, Kyungsangpuk-do, Korea, 1-4. vi. 1971 (S. Suzuki) ; 1 female, Kwangneung Kyunggi-do, Korea, 9. ix. 1982 (J. Ryu).

(2) Trissolcus mitsukurii (Ashmead, 1904)

(Figs. 1, 9, 24, 29)

Telenomus mitsukurii Ashmead, 1904, Jour. N. Y. Ent. Soc., 12: 72, female.

Telenomus mitsukurii: Brues, 1908, Gen. Insect., 80: 8.

Liophanurus mitsukurii: Kieffer, in André, 1912, Spec. Hym. Eur., 11: 61, female.

Phanurus mitsukurii: Kieffer, 1926, Das Tierreich, 48: 56, female.

Asolcus mitsukurii: Watanabe, 1951, Trans. Shikoku Ent. Soc., 2: 22, female and male.

Trissolcus mitsukurii: Masner and Muesebeck, 1968, U. S. Nat., Mus. Bull., 270: 73.

Trissolcus mitsukurii: Kozlov and Le, 1976, Ent. Rev., Washington, 55 (3): 109.

This species is similar to flavipes, but differs from the latter in having the vertex behind mid ocellus not sharply carinate, not elevated, scutellum coarsely sculptured, dull, club of antennae well formed (broad and long), mid ocellus close to vertex, frons and vertex strongly sculptured, median portion of frons distinctly carinate and face without concentric strigae.

Female : Black. Antennae reddish yellow except for club which is brownish black; junctions of scape and pedicel somewhat fuscous. Legs reddish yellow cscept for coxae which are black. Wings hyaline, veins brownish.

Head transverse as seen from above, about 3 times as broad as its median length and hardly broader than thorax. Vertex behind mid ocellus not sharply carinate, not elevated and strongly sculptured, covered with short hairs; occiput rather flat, reticulate-rugose throughout with sparse, short hairs. Frons distinctly sculptured as in vertex; median portion of frons distinctly carinate ; subocular space not bulging, coarsely reticulate-sculptured with irregular wrinkles. Eyes bare, 1.3 times as long as broad; interocular distance 1.2 times as long as eye as seen in front. Mid ocellus close to vertex; posterior ocellar distance 1.9 times as long as lateral ocellar distance. Antennae rather stout, 5-segmented, club well formed (broad and long) ; scape 4.5 times as long as broad, 3.5 times as long as pedicel; pedicel 1.9 times as long as broad, as long as first funicle segment; first 1.9 times as long as second; second rounded, 1.5 times as long as third; third and fourth distinctly transverse; club 5 -segmented, proximal first segment as long as broad, second and third transverse, fourth as long as broad and apical segment conical, 1.6 times as long as broad.

Thorax slightly broader than long $(7: 6)$ and broader than metasoma (11: 10) ; mesoscutum broad, well convex, strongly reticulate-sculptured, covered with short hairs and with sharply defined notauli in posterior portion; scutel- 
lum coarsely sculptured, slightly more coarsely sculptured than in mesoscutum and scrobiculate along the edge; metanotum short, scrobiculate and strongly sculptured ; propodeum also strongly sculptured. Fore wings 2.5 times as long as broad ; stigmalis rather long, 2.6 times as long as marginalis ; postmarginalis 1.8 times as long as stigmalis and 0.8 times as long as submarginalis. Hind wings rather broad, 3.9 times as long as broad; fringes $1 / 5$ of the greatest width of hind wing.

Metasoma slightly longer than broad (9:7) ; first tergum deeply longitudinally costate on basal half; second tergum about 1.4 times as broad as long, longitudinally striated on basal $2 / 3$ in the median portion, the rest smooth and shining; following terga distinctly transverse, punctulate all over with sparse, short hairs.

Male : Antennae predominantly yellowish, somewhat darkened toward apex. Legs entirely yellowish except for coxae dark brown. Metasoma rather less broad than in female.

Antennae 12-segmented; scape nearly equal to next three segments combined, about 3.3 times as long as broad; pedicel about 1.4 times as long as broad, shorter than first flagellar segment; first and second 1.3 times as long as broad, 1.4 times as long as pedicel; third slightly longer than broad, a little longer than fourth; fourth to sixth bead-like, a little longer than broad and barely longer than seventh to ninth; seventh to ninth nearly equal in length and width, a little slender than basal segments; apical segment conically elongate, about 2.2 times as long as broad. Otherwise like female.

Length: $1.3-1.5 \mathrm{~mm}$.

Host : Dolycoris baccarum L., Nezara antemata Scott, Longynotmus assimulans Distans, Piezodorus rubrofasciatus Fab., Gonopsis affinis Uhler, Nezara viridula L.

Distribution : Japan (Kyushu, Honshu, Shikoku) .

Specimens examined: 1 female, Mt. Hiko, Fukuoka Pref., Kyushu, 11. vii. 1969 (K. Kanmiya) ; 1 female, Mt. Hiko, Fukuoka Pref., Kyushu, 2. xi. 1968 (K. Takeno); 1 female, Mt. Hiko, Fukuoka Pref., Kyushu, 12. vi. 1968 (K. Kanmiya) ; 1 female, Miyajidake, Amakusa, Kumamoto Pref., Kyushu, 6. xi. 1961 (Y. Hirashima et T. Kawarabata) ; 1 female, Izuhara-Ariakeyama, Tsushima Is., Nagasaki Pref., Kyushu, 25. ix. 1959 (Hidaka et al.) ; 2 females, Yona, Okinawa Is., Ryukyus, 25. iv. 1965 (Y. Hirashima) ;1 female, Mt. Hiko, Fukuoka Pref., Kyushu, 20. iv. 1969 (K. Kanmiya) ; 2 females, Kamiozoegawa, Fuji, Saga Pref., Kyushu, 13. iv. 1973 (K. Yamagishi) ; 1 female, Kamiozoegawa, Fuji, Saga Pref., Kyushu, 25. ix. 1973 (K. Yamagishi) ; 1 female, Kamiozoegawa, Fuji, Saga Pref., Kyushu, 6. ix. 1973 (K. Yamagishi) ; 1 female, Kamiozoegawa, Fuji, Saga Pref., Kyushu, 4. vii. 1973 (K. Yamagishi) ;1 female, Kamiozoegawa, Fuji, Saga Pref., Kyushu, 16. vi. 1973 (K. Yamagishi) ; 2 females, Chahana, Yoronjima, Amami Is., Kagoshima Pref., Kyushu, 4. viii. 1963 (Yasumatsu and Yano) 1 male, Okinoerabu-jima, Amami Is., Kagoshima Pref., Kyushu, 6. viii. 1963 (Yasumatsu and Yano). 
(3) Trissolcus delucchii Kozlov

(Figs. 4, 10, 19)

Asolcus tumidus Delucchi,1961, Cahiers Rech. Agric., 11: 52.

Trissolcus delucchii Kozlov, 1968, Trudy vses. ent. Obshch.,5: 203, femalc and male.

Tvissolcus delucchii: Kozlov and Le, 1376, Ent. Rev., Washing., 55(3):109.

This species is similar to japonicus, but differs from the latter in having the mid ocellus separated from the vertex by more than its diameter, mesoscutum broadly rounded in frons and femora not infuscated. This is further characterized by the preoccipital carina very sharply angled behind posterior ocelli, which is obscured in the median portion, the sculpture on the frons distinctly reticulate-sculptured with scattered punctures and the scutellum closely tessellated.

Female: Black. Antennat reddish brown except for club which is dark brown. Legs reddish yellow except for coxaewhich are black. Wings somewhat tinged with brown, veins yellowish brown.

Head transverse as seen from above, about 2.Y times as broad as its median length and distinctly broader than thorax (5: 4). Vertex broad, reticulate-sculptured throughout with sparse, short hairs, this sculpture weaker than those of frons; preoccipital carina sharply angled behind eyes, but becoming obscure in the median portion. Frons well convex, strongly reticulatesculptured with scattered punctures and short hairs ; face above antennal toruli with weak transverse strigae; subocular space somewhat bulging, sculptured as in frons. Eyes rather large, bare, about 1.2 times as long as broad; interocular distance 1.3 times as long as eye as seen in front. Ocelli rather large, mid ocellus separated from vertex by more than its diameter; posterior ocellar distance 1.8 times as long as lateral ocellar distance. Antennae 11-segmented; scape 4.8 times as long as broad; pedicel 2.5 times as long as broad, 0.9 times as long as first funicle segment; first 2.5 times as long as broad, 1.8 times as long as second; second 1. 3 times as long as broad, 1.6 times as long as third; third and fourth transverse, club 5-segmented, proximal four segments slightly transverse and apical segment conical and ovate, 1.9 times as long as broad.

Thorax slightly broader than long (11:10); mesoscutum broadly rounded in front, distinctly reticulate-sculptured all over, covered with short hairs and notauli well defined posteriorly; scutellum rather broad, large, covered with rather long hairs, closely tessellated, dull and scrobiculate along the edge; metanotum very short, strongly sculptured. Fore wings rather broad, 2.5 times as long as broad; stigmalis rather long, 0.8 times as long as postmarginalis ; submarginalis 1.4 times as long as postmarginalis. Hind wings 3.9 times as long as broad; fringes $1 / 3$ of the greatest width of hind wing.

Metasoma slightly longer than broad (11: 9) ; first tergum transverse, deeply longitudinally costate; second tergum slightly transverse $(2: 3)$, longitudinally striated on basal $2 / 3$ with sparse hairs in the postero-lateral portions; following terga strongly transverse, punctulate throughout with sparse hairs. 
Male : Antennae 12-segmented; radicle, scape and pedicel yellowish brown; base of pedicel and flagellum dark brown. Radicle about $1 / 4$ as long as scape; scape 5. 2 times as long as broad, 4. 1 times as long as pedicel; pedicel 0.7 times as long as first flagellar segment; ratio of each flagellar segment as, 4.9 : $4.0: 4.0: 3.1: 3.1: 3.0: 3.0: 2.6: 2.9: 5.0$ in length, $2.2: 2.3: 2.4: 2.2: 2.0:$ 2. $2: 2.2: 2.1: 2.1: 1.8$ in width. Otherwise like female.

Length:1. 6-1. $8 \mathrm{~mm}$.

Host : Apodiphus anigolali Germ., Eurygasterintegriceps Put. (in USSR.).

Distribution: Japan (Kyushu, Shikoku), USSR., Iran. This is the first record of this species from Japan.

Specimens examined: 5 females, Okinoshima (Chikuzen), Fukuoka Pref., Kyushu, 25-28. vii. 1958 (Y. Hirashima et al.) ; 1 female, Kamiozoegawa, Fuji, Saga Pref., Kyushu, 19. v. 1973 (K. Yamagishi); 1 female, Mt. Hiko, Fukuoka Pref., Kyushu, 21. iv. 1969 (K. Kanmiya) ; 1 female, Mt. Hiko, Fukuoka Pref., Kyushu, 5. vi. 1970 (M. Miyazaki) ; 1 female, Mt. Hiko, Fukuoka Pref., Kyushu, 28, ix. 1966 (M. Honda) ; 1 female, Aoidake (Hyuga), Miyazaki Pref., Kyushu, 21. viii. 1960 (T. Hidaka); 1 female, Mt. Hiko, Fukuoka Pref., Kyushu, 26. v. 1969 (K. Takeno); 1 female, Mt. Hiko, Fukuoka Pref., Kyushu, 25. v. 1967 (S. Kimoto) ; 1 female, Mt. Hiko, Fukuoka Pref., Kyushu, 13. vi. 1966 (K. Takeno); 1 male, Mt. Hiko, Fukuoka Pref., Kyushu, 25. viii. 1968 (K. Kanmiya).

\section{(4) Trissolcus tumidus (Mayr, 1879)}

(Figs. 4, 11)

Telenomus tumidus Mayr, 1879, Verh. zool.-bot. Ges. Wien., 29: 703, female.

Aphanurus tumidus: Kieffer, in André, 1912, Spec.Hym. Eur., 11: 74, female.

Microphanurus tumidus: Kieffer, 1926, Das Tierreich, 48: 92, 36, female.

Asolcus tumidus: Remandiére, 1963, Safavi et Zomorrodi, Rev. Pat. d'Ent. agric., France: 233-238.

Asolcus tumidus: Voegele, 1901, Al Awamia, 10:20-31.

Trissolcus tumidus: Kozlov, 1968, Trudỹ vses. cnt. Obshch., 53: 188, 204, female.

Trissolcus tumidus:Kozlov and Le, 1976, Ent. Rev., Washington, 55 (3) :108.

This species is similar to japonicus in the shape of frons, but differs from the latter in having the preoccipital carina not present, although the portion distinctly edged, mid ocellus very close to vertex, pedicel as long as first funicle segment, second funicle segment not longer than broad and coloration of antennae distinctly darker.

Female: Black. Antennae brownish black except for base of pedicel tinged with yellowish brown. Legs yellowish brown except for all femora which are remarkably infuscated. Wings hyaline, veins brownish.

Head transverse as seen from above, about 3.6 times as broad as its median length and hardly broader than thorax. Vertex rather flat, reticulatesculptured throughout with sparse hairs; occiput sculptured as in vertex with sparse, short hairs; preoccipital carina not present, although the portion distinctly edged. Frons reticulate-sculptured with sparse, short hairs and face above antennal toruli very feebly transversely strigate. Eyes bare, 
1.1 times as long as broad; interocular distance rather broad, about 1.5 times as long as eye as seen in front. Mid ocellus very close to vertex: posterior ocellar distance 1.8 times as long as lateral ocellar distance. Antennae rather stout; radicle $1 / 5$ as long as scape; scape 4.5 times as long as broad, 2.9 times as long as pedicel; pedicel as long as first funicle segment, 2.4 times as long as broad; second as long as broad; third and fourth transverse; club 5-segmented, proximal four segments slightly transverse and apical segment conical, 1.3 times as long as broad.

Thorax roundly convex, covered with sparse, short hairs; mesoscutum rather broad, large, closely reticulate-sculptured, this sculpture forming wrinkles between well defined notauli; scutellum smooth and shining with scattered punctures throughout and scrobiculate along the edge ; metanotum very short, distinctly sculptured. Fore wings rather broad, 2.4 times as long as broad; stigmalis relatively long, a little more than $1 / 2$ as long as postmarginalis; submarginalis 1.2 times as long as postmarginalis. Hind wings 3.7 times as long as broad; fringes about $1 / 4$ of the greatest width of hind wing.

Metasoma slightly longer than broad (10:9); first tergum distincly transverse, deeply longitudinally costate, second tergum slightly transverse, about 1.7 times as broad as long, with longitudinal striae on basal $2 / 3$ in the median portion, elsewhere smooth and shining; following terga strongly transverse, punctulate throughout with sparse, short hairs.

Length: appros. $1.3 \mathrm{~mm}$.

Host : Eurygaster integriceps (in USSR.), Eurygaster sp. (in Morocco).

Distribution: Japan (Honshu), USSR., Morocco, Europe.

Specimens examined: 1 female, Odayama-Higasiyama (Iwasiro), Honshu, 21. v. 1916 (Y. Kurosawa).

(5) Trissolcus japonicus (Ashmead, 190 I)

(Figs. 12, 18, 31)

Dissolcus japonicus Ashmead, 1904, J. New York Ent. Soc.,12(2): 73, female.

Dissolcus japonicus: Kieffer, 1926, Das Tierreich, 48: 124-125, female.

Trissolcus japonicus: Masner and Muesebeck, 1968, U. S. Nat. Mus. Bull., 270: 72.

Asolcus plautiae Watanabe, 1954 Trans. Shikoku Ent. Soc., 4 (2): 18, female and male.

Trissolcus plautiae: Kozlov, 1968, Trudy vses. ent. Obshch., 52: 198.

Trissolcus plautiae: Kozlov and Le, 1976, Ent. Rev., Washington, 55 (3) : 109.

Trissolcus plautiae: Tachikawa, 1977, Trans. Shikoku Ent. Soc., 13: 132.

Trissolcus japonicus: Hirashima and Yamagishi, 1981, J. Fac. Agr., Kyushu Univ., 25 (4) : 153.

This species is very similar to tumidus, but differs from the latter in having the preoccipital carina present but not very sharp, mid ocellus separated from the vertex by its diameter or more, space just in front of mid ocellus smooth and shining, pedicel shorter than first funicle segment and second funicle segment distinctly longer than broad.

Asolcus plautiae Watanabe was treated as a synonym of Trissolcus japonicus (Ashmead) by Hirashima and Yamagishi (1981) according to the examination of the type specimen (USNM No. 2127) of Trissolcus japonicus. 

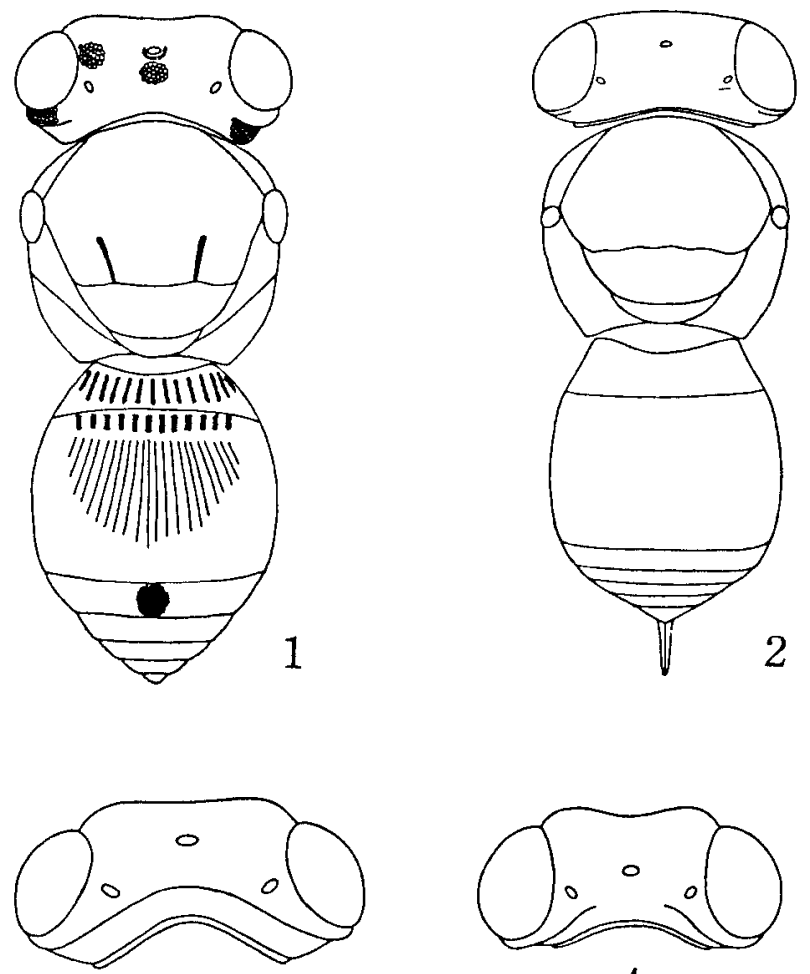

3

4

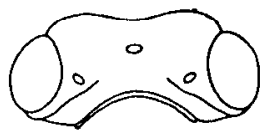

5

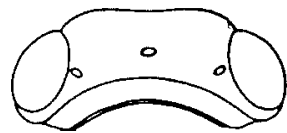

6

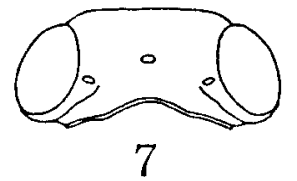

Figs. 1-2. Body of female. 1 :Trissolcus mitsukurii. 2 :Trissolcus yamagishii Ryu, sp. n. Figs. 3-1. Dorsal view of head. 3: Trissolcus flavipes; 4: T. delucchii; 5 : T. tumidus; 6: T. gonopsidis; $7:$ T. itoi Ryu, sp. n. 


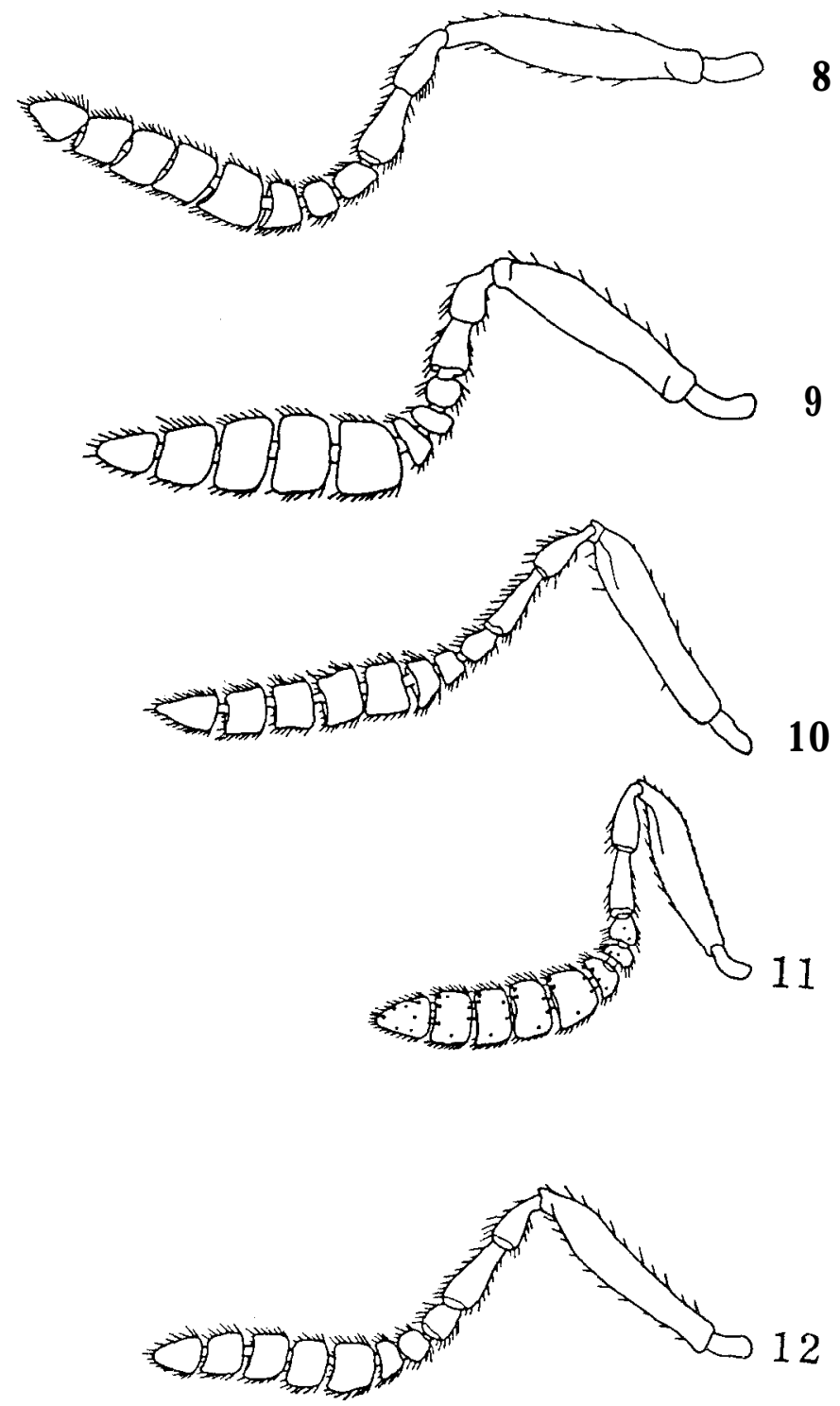

Figs. 8-12. Female antenna of Trissolcus spp. 8:T. flavipes; $9:$ T. mitsukurii; 10: T. delucchii; 11: T. tumidus; $12:$ T. japonicus. 

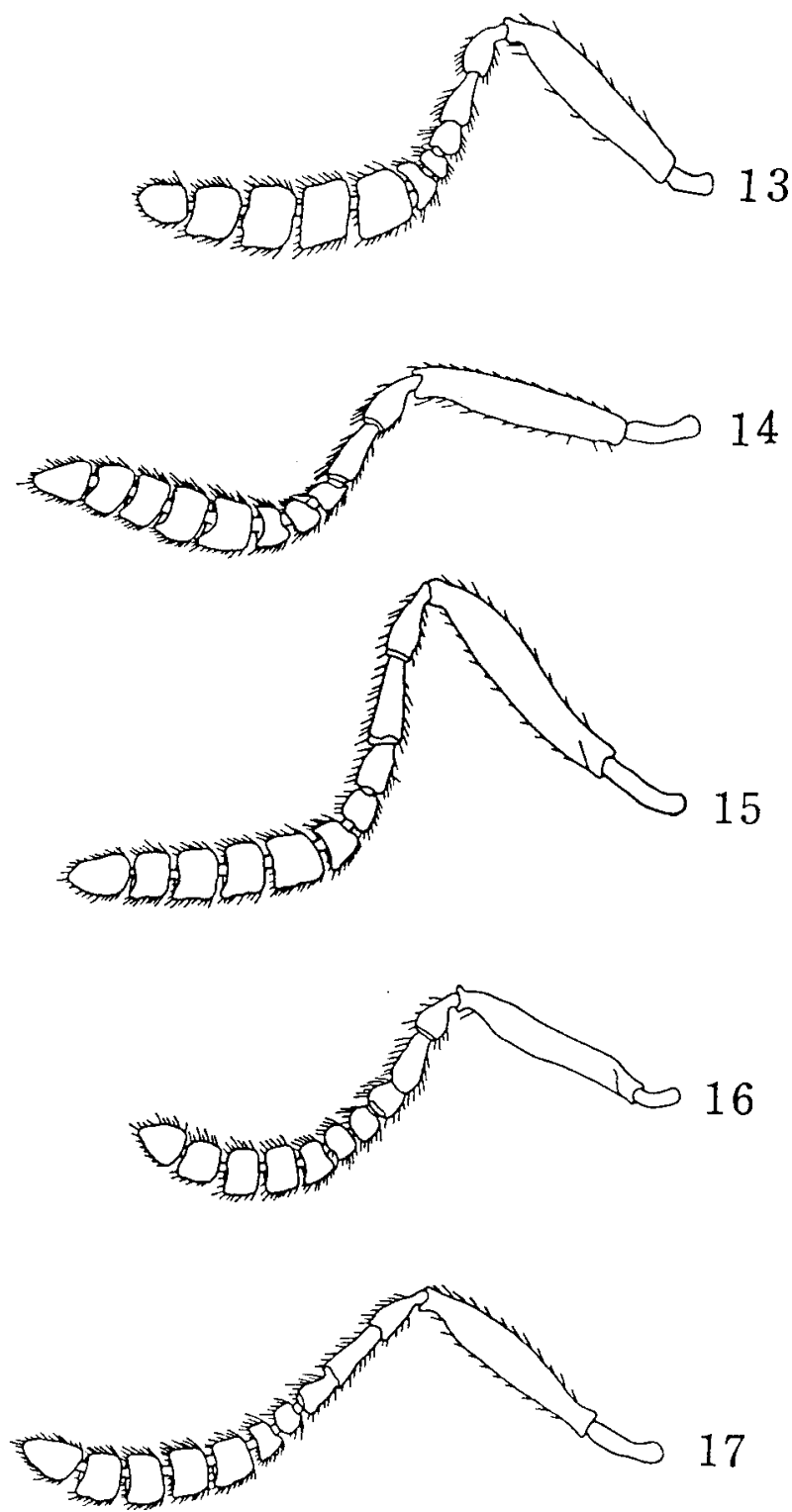

Figs. 13-17. Female antenna of Trissolcus spp. 13: T. gonopsidis; 14: T. yamagishii Ryu, sp. n.; $15:$ T. itoi Ryu, sp. n. ; 16: T. elasmuchae ; $17:$ T. nigripedius. 


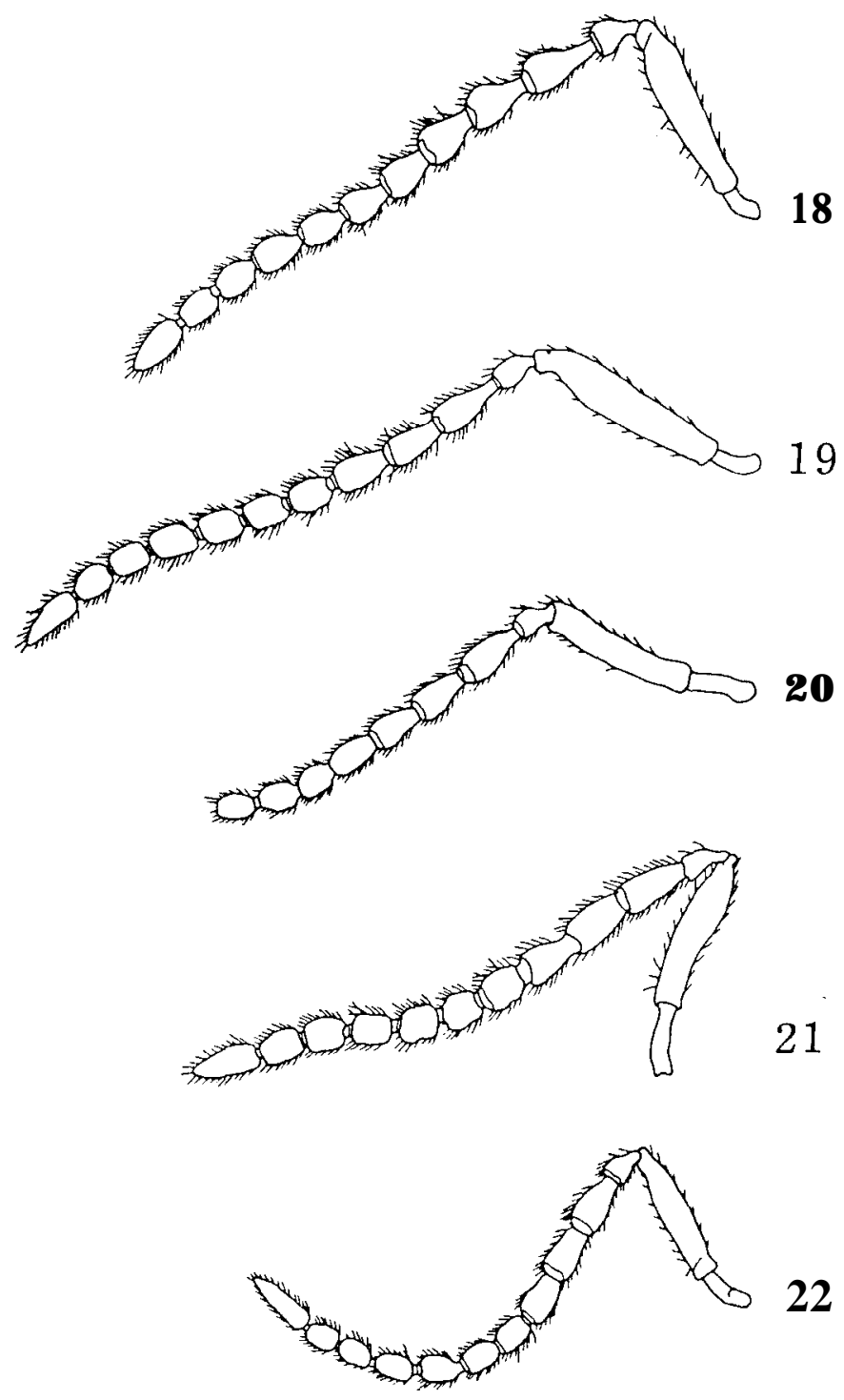

Figs. 18-22. Male antenna of Trissolcus spp. 18 : T. japonicus; 19 : T. delucchii; 20 : T. yamagishii Ryu, sp. n, ; 21 : T. itoi Ryu, sp. n.; 22: T. nigripedius. 

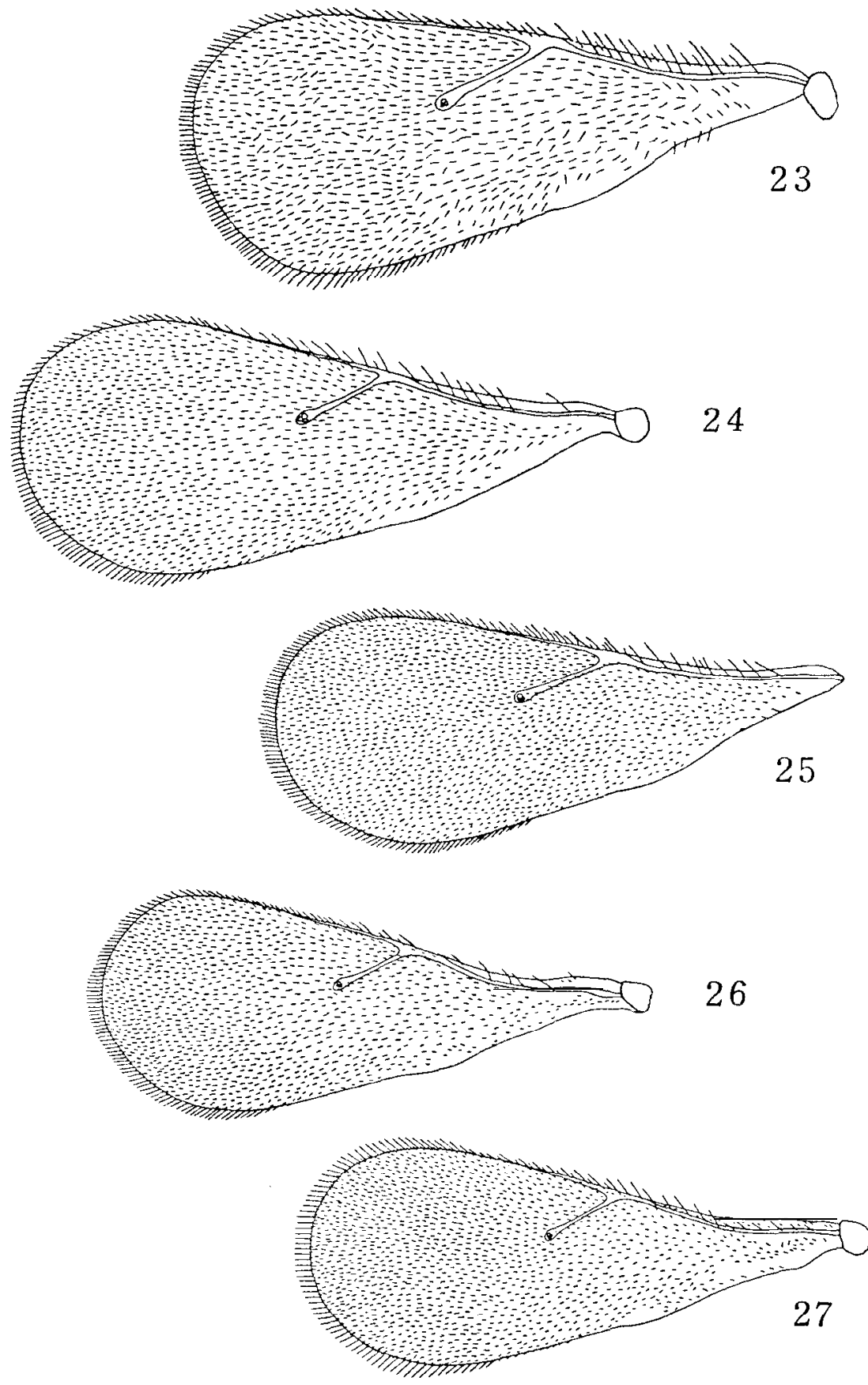

Figs. 23-27. Female fore wing of Trissolcus spp. 23: T. Alavipes; 24: T. mitsukurii ; $25:$ T. gonopsidis; $26: T$. yatnagishii Ryu, sp.n.; 27: T. itoi Ryu, sp. 11. 

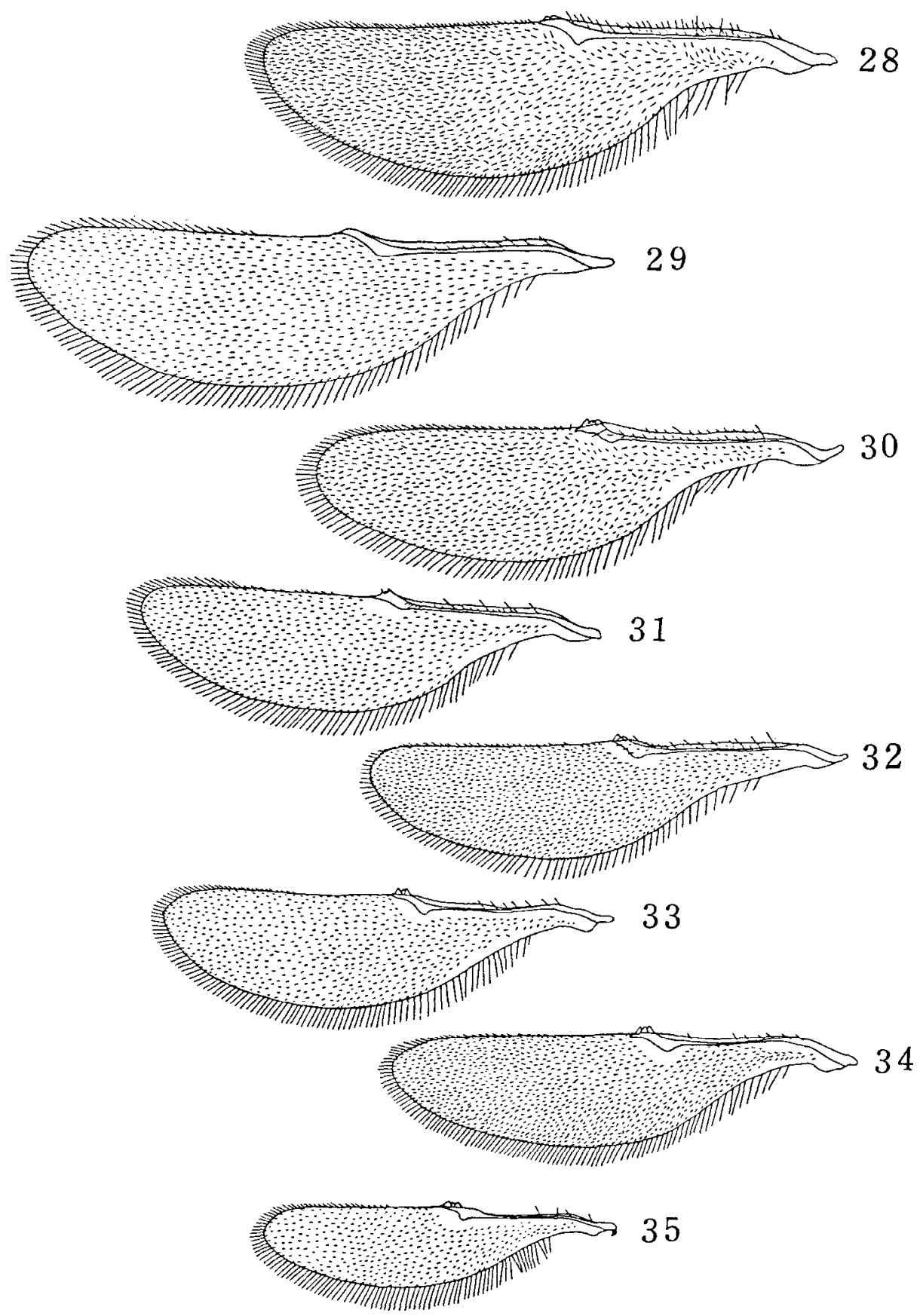

Figs. 28-35. Female hind wing of Trissolcus spp. 28: T. flavipes; 29: T. mitsukurii;30: T. delucchii; 31: T. japonicus; $32:$ T. gonopsidis; $33:$ T. itoi Ryu sp. n.; 34: T. yamagishii Ryu, sp. n.; 35: T. elasmuchae. 
Female: Black. Antennae dark brown to black except for scape and pedicel which are yellowish brown. Legs yellowish brown with coxae black and femora infuscated.

Head transverse as seen from above, about 3.3 times as broad as its median length and slightly broader than thorax (11:10). Vertex rather flat, reticulate-sculptured throughout with short hairs; occiput broadly concave, finely reticulate-sculptured with sparse, short hairs; preoccipital carina present but not very sharp. Frons reticulate-sculptured with very short hairs along inner orbit; face above antennal toruli with feeble transverse strigae ; subocular space not bulging, distinctly reticulate-sculptured. Eyes bare, 1.4 times as long as broad; interocular distance about 1.2 times as long as eye as seen in front. Mid ocellus separated from vertex by its diameter or more. Antennae 11-segmented; scape 4.7 times as long as broad, 3.9 times as long as pedicel; pedicel about twice as long as broad, shorter than first funicle segment ( $5: 7)$; first 2.7 times as long as broad, twice as long as second; second 1.7 times as long as broad, 1.6 times as long as third; third slightly transverse, 0.9 times as long as broad; fourth distinctly transverse, 0.8 times as long as broad; club 5-segmented, proximal first segment quadrate, second to fourth slightly transverse and apical segment conical, 1.2 times as long as broad.

Thorax well convex, rather broad, about 1.2 times as long as broad; mesoscutum reticulate-sculptured, covered with sparse, short silvery hairs and notauli sharply defined posteriorly; scutellum smooth and shining with scattered punctures, covered with short hairs and scrobiculate along the edge ; metanotum very short, strongly sculptured. Fore wings 2.4 times as long as broad; submarginalis slightly longer than postmarginalis (11:9), stigmalis 0. 6 times as long as postmarginalis and marginalis distinctly short. Hind wings 3.9 times as long as broad; fringes about $1 / 4$ of the greatest width of hind wing.

Metasoma rather broad, about 1.3 times as long as broad; first tergum transverse, deeply longitudinally costate all over; second tergum slightly transverse, about 1.6 times as broad as long, longitudinally striated on nearly basal $3 / 4$, with sparse, short hairs in the postero-lateral portion; third to seventh terga strongly transverse, punctulate all over with sparse, short hairs.

Male: Antennae brown except for sixth to tenth flagellar segments which are tinged with dark brown. Legs yellowish brown except for coxae and hind femora which are somewhat infuscated.

Antennae 12-segmented; radicle rather short, about $1 / 5$ as long as scape ; scape 4.5 times as long as broad, nearly equal to next three segments combined; pedicel rather short, 0.7 times as long as first flagellar segment; first 1.9 times as long as broad, 1.3 times as long as second; each flagellum longer than broad; sixth to tenth much slender than basal segments. Otherwise like female.

Length: $1.4 \mathrm{~mm}$. 
Host: Plautia stali Scott, P. splendens Distant, Elasmucha putoni Scott.

Distribution : Japan (Kyushu, Honshu, Shikoku).

Specimens examined: 2 females and 2 males, Nagasaki-shi, Nagasaki Pref., Kyushu, 6-17. vi. 1975 (T. Ishihara).

\section{Group B: Notauli absent on mesoscutum}

(6) Trissolcus gonopsidis (Watanabe, 1951)

(Figs. 6, 13, 25, 32)

Asolcus gonopsidis Watanabe, 1951, Trans. Shikoku Ent. Soc., 2: 23, female and male. Asolcus gonopsidis: Watanabe, 1954, Tans. Shikoku Ent. Soc., 4: 22, female and male. Trissolcus gonopsidis:Kozlov, 1968, Trudy vses. ent. Obshch., 52: 199.

This species is similar to delucchii, but differs from the latter in having the notauli absent on the mososcutum and the preoccipital carina is present.

This was originally described from Japan by Watanabe (1951) bred from the eggs of Gonopsis affinis Uhler.

Female: Black. Antennae reddish yellow except for club which is dark brown. Legs honey yellow except for coxae which are dark brown. Wings hyaline, veins yellowish.

Head transverse as seen from above, 2.3 times as broad as its median length and slightly broader than thorax $(9: 8)$. Vertex broad, rather flat, distinctly reticulate-sculptured throughout; occiput rather flat, closely reticulate-rugose ; preoccipital carina present, sharply angled. Frons convex, reticulate-sculptured throughout with sparse, short hairs; face above antennal toruli weakly transversely strigate, this strigae becoming weak towards mid ocellus. Eyes bare, 1.3 times as long as broad; interocular distance rather broad, about 1.5 times as long as eye seen in front. Ocelli rather large, posterior ocellar distance 1.9 times as long as lateral ocellar distance. Antennae rather stout ; scape 4.5 times as long as broad, almost equal to next five segments combined; pedicel twice as long as broad, about as long as first funicle segment; second about 0.6 times as long as first, twice as long as third; third and fourth transverse ; club 5-segmented, proximal first segment about as long as broad, second to fourth transverse and apical segment conical, ovate, 1.2 times as long as broad.

Thorax slightly broader than metasoma (11:10); mesoscutum well convex, covered with short hairs and distinctly reticulate-sculptured, this sculpture becoming foveolate on posterior half; scutellum densely reticulate, dull, much more finely sculptured than in mesoscutum and covered with hairs which are a little longer and sparser than those on mesoscutum. Fore wings rather broad, 2.5 times as long as broad; stigmalis rather long, about 0.6 times as long as postmarginalis; submarginalis 1.3 times as long as postmarginalis. $\mathrm{H}$ ind wings 4.1 times as long as broad; fringes about $1 / 5$ of the greatest width of hind wing.

Metasoma rather broad, a little longer than broad (11 : 10); first tergum transverse, longitudinally costate all over with sparse, rather long hairs in lateral portion ; second tergum a little shorter than broad, longitudinally striat- 
ed on basal $1 / 3$ with sparse, rather long hairs in postero-lateral portion; following terga strongly transverse, punctulate throughout with sparse, short hairs. Ovipositor slightly projected at the tip of metasoma.

Length : approx. $1.4 \mathrm{~mm}$.

Host: Gonopsis affinis Uhler (in Japan).

Distribution: Japan(Kyushu, Honshu, Shikoku), Korea. This is the first record of this species from Japan.

Specimens examined: 1 female, Mt. Sudo (700 m), Kyungsangpuk-do, Korea, 9-12. vii. 1971 (K. Yamagishi).

\section{(7) Trissolcus itoi Ryu, sp, $\mathbf{n}$.}

(Fig., 7, 15, 21, 27, 33)

This species is very similar to yamagishi, but chiefly differs from the latter in having the scutellum more strongly sculptured with irregular wrinkles and antennae broadly black.

This is further characterized by the preoccipital carina absent, although the portion very well convex and ridged, face above antennal toruli transversely strigate and femora remarkably infuscated.

This species was named as homalogoniae by K. Ito (1976) in his thesis for M. S. degree at Ehime University, Matsuyama. However, this name has not been published until today. Therefore, this species is described as itoi Ryu, sp. n. in this paper.

Female: Black. Antennae dark brown to black; radicle black, basal and apical tips of scape tinged with yellowish brown and club somewhat darker. Legs brown ; coxae black, femora remarkabley infuscated. Wings hyaline, veins yellowish brown.

Head strongly transverse as seen from above, about 4.1 times as broad as its median length and slightly broader than thorax; head, as seen in front, subtriangular, about 1.2 times as broad as high. Vertex rather flat, strongly reticulate-sculptured with foveolae and with sparse, short hairs; occiput broadly concave, reticulate-rugose throughout; preoccipital carina absent, although the portion very well convex and ridged. Frons rather flat, coarsely reticulate-sculptured; face above antennal toruli transversely strigate ; subocular space somewhat convex, coarsely reticulate-sculptured. Eyes bare, 1.3 times as long as broad; interocular distance about 1.3 times as long as eye as seen in front. Posterior ocelli close to inner orbit; posterior ocellar distance 1.9 times as long as lateral ocellar distance. Antenna rather slender, 11-segmented; radicle rather long, about $1 / 3$ as long as scape ; scape 4.9 times as long as broad, 3.3 times as long as pedicel ; pedicel 2.6 times as long as broad, about as long as first funicle segment; first 1.6 times as long as second; second 1.6 times as long as broad, 1.5 times as long as third; third quadrate, as long as broad; club 5-segmented, proximal first segment a little longer than broad, second to fourth slightly transverse and apical segment conical, 1.5 times as long as broad.

Thorax about as long as broad, covered with minute silvery hairs; meso- 
scutum broad, convex, strongly reticulate-sculptured, this sculpture weaker than that of scutellum; scutellum rather large, strongly reticulate-sculptured with irregular wrinkles and scrobiculate along the edge; metanotum very short, scrobiculate and sculptured. Fore wings rather broad, 3.2 times as long as broad; stigmalis rather long, $1 / 2$ as long as postmarginalis; postmarginalis 0.8 times as long as submarginalis. Hind wings 4.1 times as Iong as broad; fringes about 0.3 times as long as the greatest width of hind wing.

Metasoma oblong, 1.5 times as long as broad; first tergum strongly transverse, deeply longitudinally costate all over ; second tergum slightly transverse, 1.5 times as broad as long with longitudinal striae nearly extending to apical fourth; following terga very short, punctulate throughout with sparse, short hairs.

Male: Antennae brownish to dark brown. Legs brownish except for femora which are infuscated; hind femora darker than other femora.

Head as broad as thorax. Antennae 12-segmented; radicle rather long, 0.4 times as long as scape; scape 4.2 times as long as broad, 3.8 times as long as pedicel; pedicel 1.6 times as long as broad, 0.6 times as long as first flagellar segment, ratio of each flagellar segment as, $5.1: 4.5: 3.9: 2.6: 2.6: 2.9$ : $2.9: 3.0: 2.8: 5.0$ in length, $2.6: 2.6: 2.6: 2.6: 2.6: 2.4: 2.2: 2.2: 2.0: 1.9$ in width. Otherwise like female.

Length:1.2-1. $4 \mathrm{~mm}$.

Host: Homalogonia obtusa and Elasmucha putoni Scott (in Japan).

Distribution : Japan (Honshu, Shikoku), Korea.

Type material: Holotype : female (Type No. 2220, Kyushu Univ.), Mt. Kanagurayama, Ojiya-shi, Niigata Pref., Honshu, 19. viii. 1970 (K. Yamagishi). Paratypes: 1 female, Nose Myoken, Hyogo Pref., Honshu, 11. iv. 1976 (K. Ito); 1 female and 2 males, Hachioji-shi, Tokyo Pref., Honshu, 29. v. - 11. vi. 1975 (K. Ito); 1 female, Mt. Sanageyama, Toyota-shi, Aichi Pref., Honshu, 29. iv. 1970 (K. Yamagishi) ; 16 females, Mt. Sudo (700 m), Kyungsangpuk-do, Korea, 9-12. vii. 1971 (K. Yamagishi) ; 1 female, Mt. Sudo (700 m), Kyungsangpuk-do, Korea, 28. v. 1970 (K. Yamagishi) ; 1 female, Mt. Chunmasan, Kyunggi-do, Korea, 3. x. 1982 (J. Ryu).

(8) Trissolcus yamagishii Ryu, sp. n.

(Figs. 2, 14, 20, 26, 34)

In general appearance this species is similar to itoi, but differs from the latter in having the face above antennal toruli without transverse strigae, antennae distinctly slender and the scutellum slightly less strongly sculptured.

This new species is further characterized by the preoccipital carina absent, the mesosutum and scutellum coarsely reticulate-sculptured and the first funicle segment about twice as long as the second funicle segment.

Female : Black. Antennae yellowish brown; radicle black, apex of scape slightly infuscated and club dark brown. Legs reddish yellow except for coxae which are black. Wings hyaline, veins pale yellow. 
Head transverse as seen from above, about 3.9 times as broad as its median length and slightly broader than thorax (10: 9) ; head, as seen in front, subtriangular, about 1.4 times as broad as high. Vertex rather broad, reticu. late-sculptured throughout, covered with short hairs ; occiput broadly concave, sculptured as in vertex with sparse, short hairs; postero-lateral portion just behind eyes very narrow, sharply ridged, preoccipital carina absent behind posterior ocelli. Frons convex, reticulate-sculptured with scattered punctures near eye; marginal keels above antennal toruli with distinctly scattered punctures, without transverse strigae; subocular space well convex, coarsely reticulate-sculptured. Eyes bare, about 1.3 times as long as broad; interocular distance rather broad, 1.3 times as long as eye as seen in front. Posterior ocelli nearly situated on the top of vertex ; posterior ocellar distance about 1.8 times as long as lateral ocellar distance. Antennae rather slender, II-segmented ; radicle rather long, about $1 / 3$ as long as scape; scape 4.7 times as long as broad, almost equal to next five segments combined; pedicel twice as long as broad, as long as first funicle segment; first a little narrower than pedicel, about twice as long as second; second as long as broad; third and fourth transverse ; club 5-segmented, proximal first segment as long as broad, second to fourth transverse and apical segment conical, 1.2 times as long as broad.

Thorax covered with minute silvery hairs, a little broader than long as seen from above; mesoscutum distinctly convex, coarsely reticulate-sculptured, this sculpture becoming weaker in antero-lateral portion; scutellum rather broad, coarsely reticulate-sculptured and scrobiculate along the edge ; metanoturn very short, strongly sculptured. Fore wings 2.5 times as long as broad; stigmalis rather long, 0.6 times as long as postmarginalis and twice as long as marginalis; submarginalis 1.4 times as long as postmarginalis. Hind wings 4.2 times as long as broad; fringes about $1 / 4$ of the greatest width of hind wing.

Metasoma slightly longer than broad (10:9) ; first tergum strongly transverse with deep longitudinal costae; second tergum slightly transverse (2:3), longitudinally striated to apical fourth with sparse hairs in posterior portion; following terga strongly transverse, punctulate throughout with sparse hairs. Ovipositor projecting a little beyond the tip of metasoma.

Male: Male similar to female, differing from it by the following characters. Antennae 12-segmented, yellowish; radicle black and basal tip of pedicel infuscated. Radicle rather long, about $1 / 3$ as long as scape; scape 4.7 times as long as broad, 3.6 times as long as pedicel; pedicel shorter than first Aagellar segment (3: 5) ; first about twice as long as broad, a little longer than second; each flagellar segment longer than broad.

Length: approx. $1.3 \mathrm{~mm}$.

Distribution: Korea.

Type material: Holotype: female (Type No. 2221, Kyushu Univ.), Mt. Sudo (700 m), Kyungsangpuk-do, Korea, 9912. vii. 1971 (K. Yamagishi). Paratypes : 4 females and 1 male, Mt. Sudo (700 m), Kyungsangpuk-do, Korea, 9912. vii. 1971 (K. Yamagishi) ; 1 female, Mt. Baikbongsan, Kyunggi-do, Korea, 20. ix. 
1982 (J. Ryu).

(9) Trissolcus elasmuchae (Watanabe, 1953)

(Figs. 16, 35)

Asolcus elasmuchae Watanabe, 1954, Trans. Shikoku Ent. Soc., 4: 21, female and male.

This species is similar to yamagishii, but differs from the latter by the smaller size, length about $1.0 \mathrm{~mm}$, scutellum weakly tessellate, head, as seen from above, with frontal region well convex, occiput just behind posterior ocelli distinctly concave and longitudinal striae on the second tergum weak even on the medio-basal portion.

This species was originally described from Japan by Watanabe (1954) bred from the eggs of Elasmucha putoni (Scott).

Female: Black. Antennae yellowish except for club and radicle which are dark brown; scape and pedicel slightly infuscated. Legs honey yellow; coxae and apices of tarsi black.

Head, as seen from above, frontal region well convex, 2.8 times as broad as its median length and slightly broader than thorax (10:9). Vertex rather narrow, closely reticulate-sculptured with short hairs ; occiput just behind posterior ocelli distinctly concave, closely reticulate-sculptured ; preoccipital carina not sharply angled, merely abruptly so. Frons well convex, reticulate-sculptured with scattered punctures ; face above antennal toruli with transverse strigae. Eyes bare, rather rounded, 1.2 times as long as broad; interocular distance about 1.4 times as long as eye as seen in front. Posterior ocellar distance 1.8 times as long as lateral ocellar distance. Antennae 11-seg. mented; scape 5.9 times as long as broad, almost equal to next five segments combined; pedicel 1.8 times as long as broad, about as long as first funicle segment; second 1.2 times as long as broad, 1.4 times as long as third; third rounded and fourth transverse ; club 5-segmented, proximal four segments slightly transverse and apical segment conical, 1.3 times as long as broad.

Thorax as long as broad, covered with short silvery hairs; mesoscutum closely reticulate-sculptured; scutellum tessellate, much less strongly sculptured than in posterior portion of mesoscutum; metanotum very short, strongly sculptured. Fore wings 2.7 times as long as broad; stigmalis 0.6 times as long as postmarginalis, 1.4 times as long as marginalis. Hind wings rather narrow, 4.6 times as long as broad; fringes $1 / 5$ of the greatest width of hind wing.

Metasoma slightly longer than broad (11:9) ; first tergum transverse, deeply longitudinally costate all over; second tergum slightly transverse $(4: 5)$ with very weak longitudinal striae on extreme base; following terga strongly transverse, punctulate throughout.

Length: appros. $1.0 \mathrm{~mm}$.

Host: Elasmucha putoni Scott.

Distribution : Japan (Shikoku).

Specimens examined: 1 female, Komenono, Matsuyama-shi, Ehime Pref., Shi- 
koku, 29-30. iv. 1973 (G. Tokihiro).

(10) Trissolcus nigripedius (Nakagawa, 1900)

(Figs. 17, 22)

Asolcus nigripedius Nakagawa, 1900, Spec. Rep. Agric. Exp. Stat., 6: 17, female and male. Asolcus nigripedius: Watanabe, 1951, Trans. Shikoku Ent. Soc., 2: 21-22, female and male. Asolcus nigripedius: Watanabe, 1954, Trans. Shikoku Ent. Soc., 4: 22, female.

Trissolcus nigripedius: Masner, 1964, Acta Soc. Ent. Cech., 61: 146.

This species is similar to itoi, but differs from the latter in having the frons well convex, the scutellum without wrinkles and the antennae darker.

Female: Black. Antennae black except for junction of scape and apex of pedicel which is somewhat yellowish brown. Legs yellowish brown except for coxae which are black; femora sometimes infuscated.

Head transverse as seen from above, about 3.5 times as broad as its median length and slightly broader than thorax $(9: 8)$. Vertex broad, distinctly reticulate-sculptured and covered with very short hairs; occiput behind posterior ocelli concave, closely reticulate-sculptured with coarse, short hairs ; preoccipital carina absent, although the portion very well convex and ridged. Frons well convex, distinctly reticulate-sculptured with short hairs; face above antennal toruli with transverse strigae; subocular space well convex, distinctly reticulate sculptured. Eyes bare, rather large, about 1.2 times as long as broad; interocular distance rather broad, about 1.4 times as long as eye as seen in front. Posterior ocellar distance about 1.8 times as Iong as lateral ocellar distance. Antennae U-segmented; scape 4.6 times as long as broad, almost equal to next four segments combined; pedicel 2.5 times as long as broad, as long as first funicle segment; second 1.5 times as long as broad, 0.6 times as long as first; third quadrate, 0.8 times as long as second; fourth transverse, 1.3 times as long as third; club 5-segmented, proximal four segments slightly transverse and apical segment conical, 1.5 times as long as broad.

Thorax a little broader than long $(9: 8)$ as seen from above; mesoscutum strongly reticulate-sculptured, covered with dense short hairs; scutellum rather short, closely reticulate-sculptured and scrobiculate along the edge ; metanotum very short, scrobiculate and strongly sculptured. Fore wings 2.6 times as long as broad; postmarginalis about twice as long as stigmalis, 0.9 times as long as submarginalis. Hind wings 3.9 times as long as broad; fringes a little more than $1 / 5$ of the greatest width of hind wing.

Metasoma slightly longer than broad (11: 9), 1.2 times as long as thorax; first tergum strongly transverse, longitudinally costate; second tergum sligthly transverse, about 1.4 times as broad as long and longitudinally striated on basal half, elsewhere shining with sparse hairs in postero-lateral portion; following terga strongly transverse, punctulate throughout with sparse hairs.

Male: Antennae 12-segmented, brownish black; sixth to tenth flagellar segments somewhat darker than other segments; first to third broader than next flagellar segments. Radicle about $1 / 3$ as long as scape; scape about 3 
times as long as pedicel; pedicel 0.6 times as long as first flagellar segment; ratio of each flagellar segment as, $2.1: 1.9: 1.6: 1.4: 1.3: 1.3: 1.3: 1.3: 1.3:$ 2.3 in length, and $1.2: 1.2: 1.2: 1.1: 1.1: 1.1: 1.0: 0.9: 0.8: 0.8$ in width. Otherwise like female.

Length: 1. 2-1. $5 \mathrm{~mm}$.

Host: Dolycoris baccarum L. (in Japan).

Distribution: Japan (Kyushu, Honshu, Hokkaido, Shikoku), Korea. This is the first record of this species from Korea.

Specimens examined: JAPAN: 1 female, Mt. Hiko, Fukuoka Pref., Kyushu, 17. vi. 1968 (K. Kanmiya) ; 3 females, Mt. Tachibana, Fukuoka Pref., Kyushu, 6. v. 1968 (N. Yoshida) ; 1 female, Mt. Hiko, Fukuoka Pref, Kyushu., 1. viii. 1968 (K. Kanmiya) ; 3 females, Mt. Hiko, Fukuoka Pref., Kyushu, 13. vi. 1966 (K. Takeno) ; 3 females, Mt. Hiko, Fukuoka Pref., Kyushu, 22. vi. 1968 (K. Kanmiya) ; 2 females, Mt. Hiko, Fukuoka Pref., Kyushu, 7. vii. 1968 (K. Kanmiya) ; 7 females, Mt. Hiko, Fukuoka Pref., Kyushı, 20. iv. 1969 (K. Kanmiya) ; 1 female, Mt. Hiko, Fukuoka Pref., Kyushu, 15. vi. 1969 (K. Kanmiya) ; 1 female, Mt. Hiko, Fukuoka Pref., Kyushu, 30. v. 1969 (K. Takeno); 1 female, Mt. Hiko, Fukuoka Pref., Kyushu, 23. vi. 1968 (K. Kanmiya) ; 1 female, Mt. Hiko, Fukuoka Pref., Kyushu, 14. vi. 1969 (K. Kanmiya) ; 3 females, Mt. Hiko, Fukuoka Pref., Kyushu, 11. vii. 1969 (K. Kanmiya) ; 1 female, Mt. Hiko, Fukuoka Pref., Kyushu, 5. vi. 1970 (K. Kanmiya) ; 1 female, Mt. Hiko, Fukuoka Pref., Kyushu, 4. vi. 1968 (K. Takeno); 1 female, Mt. Hiko, Fukuoka Pref., Kyushu, 14. vi. 1959 (K. Yasumatsu); 1 female, Cape Sata, Kagoshima Pref., Kyushu, 29. iv. 1962 (A. Nakanishi) ; 1 female, Kamiozoegawa, Fuji, Saga Pref., Kyushu, 6. ix. 1973 (K. Yamagishi) ; 1 female, Kamiozoegawa, Fuji, Saga Pref., Kyushu, 10. viii. 1973 (K. Yamagishi) ; 1 female, Rubesu, Shibetsu, Nemuro, Hokkaido, 25-28. viii. 1971 (K. Yamagishi) ; 1 female, Kamiibo, Toyota-shi, Aichi Pref., Honshu, 28. vi. 1970 (K. Yamagishi) ; 1 female, Mt. Kisokomagatake, Nagano Pref., Honshu, 16. vii. 1967 (H. Taguchi) ; 1 female, Mt. Myohjingamori, Ehime Pref., Shikoku, 30. vii. 1974 (K. Ito) ; 1 male, Mt. Hiko, Fukuoka Pref., Kyushu, 5. vi. 1970 (K. Kanmiya). KOREA: 4 females, Mt. Sudo (400 m), Kyungsangpuk-do, Korea, 17-18. vii. 1971 (K. Yamagishi) ; 2 females, Mt. Sudo $(700 \mathrm{~m})$, Kyungsangpukdo, Korea, 9-12. vii. 1971 (K. Yamagishi).

\section{REFERENCES}

Ashmead, W. H., 1893 A monograph of the North American Proctotrupidae. Bull. U.S. nat.Mus., 45: 1-472

Ashmead, W. H. 1903 Classification of the pointed-tailed wasps, or the superfamily Proctotrypoidea. J. New York ent. Soc., II: 86-99

Ashmead, W. H. 1904 Descriptions of new Hymenoptera from Japan. Ibid., 12: (2) : 65-83

Brues, C. T. 1908 Hymenoptera Fam. Scelionidae. Genera Insectorum, fasc. 80: 1-59, 2 pls.

Delucchi, V. L. 1961 Le complex des Asolcus Nakagawa(Microphanurus Kieffer) (Hymenoptera, Proctotrupoidea), parasites oophages des punaises ses cèréales au Macroc et au Moyen Orient. Cah. Reck. agron., Rabat, 14: 41-67

Eady, R. D. 1968 Some illustrations of microsculpture in the Hymenoptera. Proc. R. ent. Soc. Lond., (A), 43 (4-6) : 66-72 
Hirashima, Y. and K. Yamagishi 3981 Redescriptions of some Japanese Scelionidae preserved in the United States National Museum (Hymenoptera, Proctotrupoidea). J. Fac. Agr., KyushuUniv., 25 (4) : 1533159

Kieffer, J. J. 1910 Hymenoptera Fam. Scelionidae. Genera Insectorum., fasc.80 B:61-112, $1 \mathrm{pl}$.

Kieffer, J. J. 1926 Scelionidae. Das Tierreich, 48: 1-131

Kozlov, M. A. 1968 Telenominae (Hymenoptera, Scelionidae) of the Caucasus-egg parasites of hemipterous grain pests. Trudy uses. ent.Obshch., 52: 188-223 (In Russian)

Kozlov, M. A. and S. H. Le 1976 Palearctic species of the Trissolcus flavipes Thomson group (Hymenoptera, Proctotrupoidea, Scelionidae). Ent. Oborr., 55 (3) :657-667 (In Russian). Translated in: Ent. Rev., Washington, 55 (3): 108-114

Krombein, K. V., P. D. Hut-d., Jr., D. R. Smith and B. D. Burks 1979 Catalog of Hymenoptera in America North of Mexico, 1: 1-1198. (Scelionidae, by C. F. W. Muesebeck, pp. 1150-1171)

Masner, L. 1964 A comparison of some Nearctic and Palearctic genera of Proctotrupoidea (Hymenoptera) with revisional notes. ActaSoc.ent. ̌́SR., 61 (2): 145-146

Masner, L. 1976 Revisionary notes and keys to world genera of Scelionidae (Hym., Proct.). Mem. Ent. Soc. Canada, 97: 1-87

Masner, L. 1979 Pleural morphology in Scelionid wasps (Hym.: Scel.) -an aid to higher classification. Can. Ent., 111: 1079-1087

Masner, L. 1980 Key to genera of Scelionidae of the Holarctic region, with descriptions of new genera and species (Hym.: Proctotrupoidea). Mem. Ent. Soc. Canada, 11 a: 154

Masner, L. and C. F. W. Muesebeck 1968 The types of Proctotrupoidea (Hymenoptera) in the United States National Museum. Bull. U.S. nat. Mm., 270: 1-143

Mayr, G. 1879 Ueber die Schlupfwespengattung Telenomus. Verh. zool.-bot. Gcs. Wien, 29: 697-714

Nakagawa, H. 1900 Illustration of some Japanese Hymenoptera parasitic on insect eggs. I. Spec. Rep. Agric. Exp. Stat., 6: l-26, 7 pls. (In Japanese)

Tachikawa, T. 1977 Hymenopterous parasites of the eggs of Plautia stali Scott (Hemiptera: Pentatomidae) in Japan. Trans. Shikoku Ent.Soc., 13: 132

Watanabe, C. 1951 On five Scelionid egg-parasites of some Pentatomid and Coreid bugs from Shikoku, Japan (Hymenoptera: Proctotrupoidea). Tram. Shikoku Ent.Soc., 2 (2): $17-26$

Watanabe, C. 1954 Discovery of four new species of Telenominae, egg-parasites of Pentatomid and Plataspid bugs, in Shikoku, Japan (Hymenoptera : Proctotrupoidea). Ibid., $4(2): 17-22$ 